\title{
The development of the dialogic culture as a "centaur problem" of the professionalization of the future educators
}

\author{
Natalya Tokareva* \\ Kryvyi Rih State Pedagogical University, Kryvyi Rih, 50086, Ukraine
}

\begin{abstract}
The article deals with the analysis of the problem of developing the dialogic culture of the future educators in terms of their professionalization. The author has shown that the congruent coverage of the specifics of forming an individual as an entity of professional activity in the continuum of the modern culture can be carried out only within the dialogic mode. It has been found that de-valuing the psychological component and accumulating systems of algorithmic tasks of the test type in the practice of the professional training makes it impossible to develop the communicative (and especially dialogic) culture of a specialist. The dialogic culture is interpreted by the author as an integrative construct of an individual, i.e. a set of communicative and technological indicators of the systemic behaviour (and professional-role one in particular) of the activity entity. The empirical research procedure had as its objective to outline the psychological tendencies in the development of the indicators for the communicative culture of the professionalization entities (bachelor degree and master degree students) in the modern educational space. The dominance of the monologic model of communication in the respondents' behavioural scenarios and the absence of the self-management development dynamics in communication have been statistically corroborated. The findings of the research are interpreted as the theoretical foundation of a modern model for the dialog-phenomenological interaction that is adequate to the new challenges of the time and the educational reform principles.
\end{abstract}

\section{Introduction}

The cosmopolitan tendencies of the post-industrial era of the civilization development, the continual character of the renewal of the living space in the $21^{\text {st }}$ century lead to permanent entropy, chaotic nature, dramatization of the scenarios of being and worldview positions of the present-day "average person". The multimodality and the accessibility of informational content under the unstable conditions of the life's activities exacerbate the contradiction of the existential personal choices of the cultural and historical continuum of the self-fulfilment of an individual.

The involvement of a person in the various aspects of social structures and relationships is accompanied by considerable stress on the psyche. The "destruction" of the inner integrity and the affective cognitive emotions of a person under the unstable conditions of the life's activities reach such a level that the threat of psychological maladjustment, mental and somatic diseases of the psychogenic spectrum becomes real. Social apathy, stereotyping of thinking strategies, conformism, avoiding (or even fearing) the manifestation of creativity in constructing one's own life concepts are often human reactions to the socialpsychological situation of uncertainty. The constructive life creation by the individual in today's paradoxical world is largely related to adaptation scenarios that are interpreted as active processes of interaction with the social environment, one of the most important forms of that interaction being professional activity.

Professionalism of the individual is recognized an important constant of the efficient implementation of the professional activity [1], which conditions not only the possibility of skilled work, but also the optimization of the process of modelling personal constructs, ensuring integrity, the constructive orientation [2-4] and the resource potential [5-7] of the activity entity. A significant vector of an individual's professionalization is undoubtedly high-quality professional education, whose development potential is marked by the orientation to a new level of the development of a person capable of making responsible choices and inclined to move in a socially constructive direction of selffulfilment. And, first of all, this concerns pedagogical education, whose quality determines the efficiency of the formation of worldview mindset of the person of the new generation, the so-called generation-next that is filled with the potential resources for the affirmation of their "otherness", capable of independently comprehending a new experience of the efficient interpersonal interaction under the modern conditions of life creation.

In the context of the above, the issues of rethinking the paradigmatic aspects of the socio-cultural and professional identity, its aesthetics under the conditions of an unstable information society are becoming

\footnotetext{
*Corresponding author: tokareva152681@gmail.com
} 
particularly relevant. At the same time, the congruent coverage of the specificity of an individual's formation as an entity of self-development in the continuum of the dynamic worlds of the modern culture can undoubtedly be effected within the dialogic mode [8-11, 13-17]. After all, the assimilation of the individual's social experience, the accumulation of social and personal behavioural patterns (including professional and role-playing ones) are possible only under the conditions of communication, which is characterized by entity-toentity links and relationships $[4 ; 13 ; 14 ; 18 ; 19]$. "Forming a culture of dialogue is one of the real ways of overcoming the depth of contradictions of the modern culture and a prerequisite for the proper communication between civilized people, - N.G. Uskova emphasizes, because a dialogue is the foundation of being and worldview, of the development of cognitive and mental activity of a person" $[10$, p. 3$]$. In a dialogue, a person constitutes and reveals himself/herself as an individual, as an entity of self-determination, free self-definition in relation to reality thus realizing his/her own "identity that acquires its full and universal expression precisely in the process of dialogue. One voice completes nothing and resolves nothing. Two voices are the minimum of life, the minimum of being" [19, p. 121].

However, according to the analysis of the scientific literature $[10,20-22]$ and our own experience of pedagogical activities, professional training of future specialists (and educators in particular) takes place mainly outside the continuum of the dialogue of cultures, without taking into account the dynamic tendencies and the paradoxical nature of the modern socio-cultural space. The digitalization of educational systems and the widespread introduction of the knowledge control tests do not contribute to the development of the dialogic culture of the education entities either, which creates a paradox of the social consciousness, - the dimension of the "centaur problem".

Zh.T. Toshchenko's research convincingly proves that "centaur problems" are generated by the contradictions of life experience and testify not only to the existence of incompatible values, attitudes in particular social groups, but also cultivate such contradictions, which leads to incompatible statements and actions [23, p. 11]. A "centaur problem" manifests itself when individually diverse actions are rational, but combined into a system reveal not only incoherence, but also total contrariety, incompatibility with each other [23, p. 12].

In this context, to the best of our belief, devaluing the psychological component and accumulating systems of algorithmic tasks of the test type in the practice of the professional training makes axiomatic the impossibility to develop the communicative (and especially dialogic) culture of a specialist. After all, the assimilation by a person of the socio-cultural and professional experience, the verification of subjective behavioural patterns in the modern information environment are possible only on the basis of the active communication $[4,10,16,17,20$ $22,24,25]$ that implies the intensification of the existing communicative intentions, their translation into a more technological form (involving the use of a linguistic code apparatus and other semiotic systems), which ensures the achievement of a predicted result as opposed to a random process.

In order to prove the above, a theoretical and empirical research was carried out with the purpose of outlining the psychological tendencies of the development of the communicative culture indicators for professionalization entities (bachelor degree and master degree students) in the modern educational space.

The conceptual idea of this research was the proposition that the development of the communicative culture (and dialogic one in particular) of the future educators is an invariant indicator of an efficient pedagogical process determined by the requirements of the modern information space and the tendencies of the individual development of the professionalization entities.

\section{Research methods and techniques}

The contradictory nature of the problematic field of studying the psychological tendencies of the development of the professionalization entities' communicative (and in particular dialogic) culture determines the requirements for the correct formation of the sample cohort for the empirical component of the research. Given the sensitivity of adolescents to the transient nature of the socio-cultural space of the modern information environment and the sensitivity of this age period persons to the formation of the experience of the professional and role-playing behaviour, representatives of the student community were selected as the entities of the research program.

The research sample consisted of 226 persons: 123 second-year bachelor degree students (17-18 years of age) and 103 master degree students (20-22 years of age) of Kryviy Rih State Pedagogical University (Ukraine).

In order to more fully define the general dynamics of the phenomenon under research, the target sample cohort was supplemented by the juvenile respondents $\left(435^{\text {th }}\right.$ and $6^{\text {th }}$ grade pupils (11-12 years of age) of one of the city of Kryviy Rih secondary schools), whose answers were interpreted by us as a model for the presentation of the communicative culture in the genesis of childhood (younger juvenile age).

The systemic-integrative content of the subject field of the students' communicative culture indicators research determined the structuring of the logic of the research program in terms of the implementation of the genetic method of systemic research, which states the need to analyze the patterns of functioning and transformation of mental phenomena, the correlation of the actual and the potential in the mental development.

In order to achieve our goal and to implement the program of studying the development features of the communicative culture of students in the period of their professionalization, we used the following psychodiagnostic methods that were adequate to the research subject:

- S. L. Bratchenko's "Individual's orientation in communication" method that makes it possible to assess the importance of the dialogic and monologic vectors of 
an individual's orientation in the "I - the Other one" coordinates;

- "The study of the capability for self-management in communication" method (questionnaire) intended to determine the mobility and adaptability of an individual in different situations of communication [26, p. 164166].

The primary data processing was carried out by calculating the average values of the material obtained. The IBM SPSS Statistics 19 ("Statistical Package for the Social Science") computer program was used to compile and analyze the empirical material. The variables were checked for the standardized character of the distribution of a feature.

\section{Findings and discussions}

The theoretical and methodological review of the issue of the development of the communicative culture of students in the period of their professionalization [20, 21, 24] makes it possible to interpret the communicative culture of students as a system-forming component of the general and professional culture of the future specialists.

In general, we share the conceptual approach of L. A. Aukhadeyeva, who views the communicative culture as the ability of an individual to integrate his/her own consciousness into the global (not narrowly professional) space of social consciousness and thus to achieve significant results in his/her personal and professional development [20, p. 228]. One of the forms of implementing the communicative culture of an individual is dialogic culture [10, 16, 17], which can be interpreted as an integrative construct of an individual, i.e. a set of communicative and technological indicators of the systemic behaviour (and professional-role one in particular) of the activity entity.

In the context of the philosophical and anthropological worldview, a recourse to a dialogue as an explanatory principle of constructing subjective reality is traced. M. M. Bakhtin [18, 19], for example, interprets dialogue as a special form of interaction between equal and equivalent consciousness entities: everything vital is inherently dialogic [18, p. 327]. The existence of man, as the philosopher points out, is directly related to "the other" $[11,18]$, which conditions the formation of the worldview positions of an individual (the value-meaning intentions), the assimilation of the repertoire of the comprehensible roles and behavioural strategies in terms of the interpersonal interaction (those roles and strategies denoting the interpersonal intention capacity of the dialogue). The event-related content of the dialogue (the implementation of the "event of being") conditions its definition as the space of spiritualsemantic and moral-ethical dimensions of the human life, which transform the abstract-theoretical and conditionally potential attitudes to the discourse of life into real actions and practical deeds of a person as a responsible entity of being and co-being. So consequently, the development of the dialogic culture of an individual facilitates the existential self-affirmation, which in turn promotes, supports (and sometimes significantly influences the process of) decision-making and making choices in the context of the entity's mental field.

In the context of the aforementioned, we tested individual personality indicators for the maturity of the dialogic culture of schoolchildren and students within the sample cohort.

The analysis of the dialogic and monologic vectors of an individual's orientation in the "I - the other one" coordinates (data obtained using S. L. Bratchenko's "Individual's orientation in communication" method) made it possible to identify the development tendencies of the communicative orientation of the respondents at different stages of their professionalization (Table 1).

Table 1. The dynamics of the identification of the types of orientation in communication among the juveniles and adolescents of the sample cohort.

\begin{tabular}{|c|c|c|c|}
\hline $\begin{array}{l}\text { Age groups } \\
\text { Types of }\end{array}$ & \begin{tabular}{|c|}
$\begin{array}{c}11-12 \text { years } \\
\text { of age } \\
(N=43)\end{array}$ \\
\end{tabular} & $\begin{array}{c}\text { 17-18 years } \\
\text { of age } \\
(N=123) \\
\end{array}$ & $\begin{array}{c}\text { 20-22 years } \\
\text { of age } \\
(N=103) \\
\end{array}$ \\
\hline $\begin{array}{l}\text { the individual's } \\
\text { orientation in } \\
\text { communication }\end{array}$ & \multicolumn{3}{|c|}{ Average values (Mx) } \\
\hline $\begin{array}{l}\text { Dialogic } \\
\text { orientation }\end{array}$ & 2.37 & 0.71 & 0.33 \\
\hline $\begin{array}{l}\text { Monologic } \\
\text { orientation }\end{array}$ & 3.47 & 3.85 & 3.92 \\
\hline Authoritarian & 2.44 & 3.05 & 3.55 \\
\hline Manipulative & 2.69 & 2.93 & 3.96 \\
\hline Alterocentric & 3.75 & 5.54 & 4.50 \\
\hline Conformist & 6.00 & 5.17 & 4.19 \\
\hline Indifferent & 2.50 & 2.54 & 3.38 \\
\hline
\end{tabular}

The analysis of the average values $(\mathrm{Mx})$ of an individual's orientation tendencies in the communication among schoolchildren and among students recorded the dominance of the monologic model (the maximum values are presented in the master degree students' group $(\mathrm{Mx}=3.92))$.

The dialogic orientation of the students' communicative behavior is pronounced at the minimal level (in particular if compared with the indicators for younger juveniles).

The differential analysis of the monologic orientation in the genesis of the students' professionalization makes it possible to state:

- an increase in the students' propensity for the manipulative, authoritarian and indifferent (a behavioural pattern oriented to the rigid nature of communicative scenarios) models of the communicative behaviour (the maximum $\mathrm{Mx}$ values are presented in the master degree students' profile);

- a decrease in the level of the tendency to the conformist behaviour (the maximum $\mathrm{Mx}$ values are detected for the teenage schoolchildren, which is related to the childlike dependence of the juvenile respondents on the people of authority);

- the instability of the development of the alterocentric model of the communicative behaviour in the process of the respondents' professionalization (the maximum $\mathrm{Mx}$ values are presented in the bachelor degree students' profile); this model is characterized by the refusal of the students of this group (II year study) from the equality in 
communication in favour of the interlocutor, i.e. the orientation to the "object" position for themselves.

The Spearman rank correlation method was used to corroborate the significance of the data obtained. The method made it possible to clarify the direction and the strength of the correlation between the types of the respondents' communicative behaviour in the age dynamics. The following was found:

- during the process of the higher education, the respondents' dialogic orientation in communication decreases statistically significantly $(\rho=-0,209)$ at the average level of statistical significance $(p \leq 0,01)$;

- the level of the conformist model of the monologic orientation decreases statistically significantly $(\rho=-0,180)$ at the average level of statistical significance $(p \leq 0,01)$, which indicates the efforts of the students (and especially those of the master degree course) to assert their own interests in the process of communication while ignoring the needs of the others; - the manipulative type of the monologic orientation increases with age statistically significantly $(\rho=0,252)$ at the average level of statistical significance $(p \leq 0,01)$; - the level of the authoritarian $(\rho=0.106)$ and indifferent $(\rho=0,128)$ types of the communicative behaviour increases at a sufficient level of statistical significance $(p \leq 0,05)$.

Although the relationships found during the correlation analysis process are weak $(0,01<\rho \leq 0,29$ and $-0,29<\rho \leq-0,01)$, they signify the potential vectors for the deployment of the key communicative tendencies of an individual's orientation in communication during the controversial period of professionalization.

The significance of the differences in the identification of the types of the monologic orientation in communication among students of the different academic periods was also corroborated by means of the variance analysis (the correctness of its use was proved by the Levene homogeneity-of-variance criterion at $p>0,05)$. The one-way variance analysis revealed statistically credible meaningful differences between the $\mathrm{Mx}$ values in different age groups of the respondents by such types of the monologic orientation of an individual in communication as manipulative $(F=4,5$ at $0,001=p \leq 0,05), \quad$ alterocentric $\quad(F=3,3$ at $0,012=p \leq 0,05)$ and conformist $(\mathrm{F}=3,8$ at $0,005=p \leq 0,05)$. Communication are statistically insignificant (at $p>0,05$ ), $\mathrm{Mx}$ values compared differ only quantitatively.

The differences between the empirical research indicators for the manifestation of the authoritarian and indifferent types of orientation in the juveniles'.

We have also explored such an indicator of the communicative culture of an individual as the capability for self-management, which outlines the dynamics of the respondents' adaptability in different situations of the social interaction.

"The study of the capability for self-management in communication" questionnaire was used $[26$, p. 164166]. The generalized results of the psycho-diagnostic measurement of that feature in the respondents of different age groups are shown in Table 2.
Table 2. Self-management capability dynamics for the juveniles and adolescents of the sample cohort.

\begin{tabular}{|c|c|c|c|}
\hline Age groups & $\begin{array}{c}11-12 \\
\text { years of } \\
\text { age } \\
(N=43)\end{array}$ & $\begin{array}{c}\mathbf{1 7 - 1 8} \\
\text { years of } \\
\text { age } \\
(N=123)\end{array}$ & $\begin{array}{c}\mathbf{2 0 - 2 2} \\
\text { years of } \\
\text { age } \\
(N=103)\end{array}$ \\
\hline parameters & \multicolumn{3}{|c|}{ Average values (Mx) } \\
\hline $\begin{array}{l}\text { Level of self- } \\
\text { management in } \\
\text { communication }\end{array}$ & 14.32 & 14.23 & 13.54 \\
\hline
\end{tabular}

The analysis of the data obtained makes it possible to ascertain the dominance in the respondents of the sample cohort of the medium level of the capability for the selfmanagement in communication (with a standard deviation of 2,78 on the questionnaire scale within the range of $8-17$ points), which denotes the impulsive rebelliousness and the renunciation of responsibility that is inherent in the respondents of the older age group.

Checking the significance of the dynamics indicators for the level of the development of self-management in communication in the respondents of different age groups using the one-way ANOVA method (the correctness of the use of this method is corroborated by the Levene homogeneity-of-variance criterion at $p>0,05)$ made it possible to ascertain the absence of statistically credible meaningful differences between the groups of juveniles and adolescents $(F=0,134$ at $0,87=p>0,05)$.

The Mx values of the level of self-management in communication between the respondents of different ages (and therefore of different stages of professionalization) vary only quantitatively, which indicates that there is no constructive development of self-management skills in communication during the process of the higher education.

\section{Conclusions}

It should be acknowledged that the absolutization of certain cognitive positions (and in particular the technologization of the core pedagogical training of specialists) cannot in principle ensure the unambiguity of the solution of the problem of the development of dialogic culture of future specialists, and, accordingly, leads to the emergence of a "centaur situation", whereby the altered living environment conditions the nonadaptive logic of behavioural scenarios of a person.

The results of empirical investigation certify about the absence of object-oriented influence in the educational institutions regarding the development of dialogical culture of pupils and dialogical model of professional interaction in the model "Student Teacher" without violation of professionallycommunicative balance.

The mastering by a life creation's entity of the dynamic function of interpretation (in the form of multientity interpretive constructs: narration, dialogue, reasoning, judgment) makes it possible to solve a number of problems of personal development: it eliminates the semantic uncertainty of the social existence situation and in particular in the field of professional activity; it explains the need to correlate (or 
not to correlate) one's own versions, thoughts and constructs with other people's versions; it implements the reflection of one's own assessments and judgments thus conditioning the certainty and constancy of the criteria for such a reflection \& etc. The communicative (and above all dialogic) culture of an individual signifies the deepening of the individual's narratives, intensifies the overall development of the individual under the conditions of the polylogue of cultures.

Dialogization of educational system creates the conditions to re-analyze integral "I" of the subjects of teaching and educational process as inter-discursive activity.

The above idea nourishes the concept of tolerance, forms the theoretical foundation of a modern model for the dialog-phenomenological interaction that is adequate to the new challenges of the time and the educational reform principles.

The format of reflexive-dialogical professional interaction has been selected as a strategic vector of modelling process organization of rational personality constructs.

Functional modelling of communicative modelling of teachers' personality profile under the conditions of the present-day educational environment is interpreted as an act of continuous formatting of the subjective psychic reality, i. e. of a unique model of personal dimensions of a human being's socio-cultural environment.

The communicative aspects of the flexible introduction of functional programs for educational environment humanization is a necessary condition to ensure the long-term psychological support for multivariate extension and refinement of the system of personality constructs of professional activity agents in the context of their modelling. Activation of the agent's potential (the internal determination of behaviour) and goal-oriented social and psychological motivation to create meaningful scenarios of personality's creative life (the external determination of adaptive behaviour) have been identified as relevant areas for modelling personal constructs of teachers.

Constructive dialogue strategies of communication are the beginning of the adolescent productive life creativity and demand aimed modeling in the active person becoming period.

The introduction of dialogue system in the education is a crucial factor for development of personal potential of each participant during the teaching and educational process.

The attractors of the process of communicative modelling of personal constructions are the mechanisms of context making of communicative contour of phrases in the dialogue situation.

We are convinced that the research findings presented in this article will contribute to solving a wide range of theoretical and practical problems related to understanding the dynamic context of the semantics of the psychological support for professionalization.

We see the prospects of the research in studying the semantic features of the "image of one's own changes" of the professionalization entities, which will make it possible to build guidelines for the work of psychologists with students in the context of preventing the difficulties of the development of the dialogic culture as a whole.

\section{Reference}

1. S.A. Druzhilov, Psihologiya vyizhivaniya $v$ sovremennom mire (The psychology of survival in the modern world). (Gumanitarnyiy Tsentr, Harkov, 2012)

2. E.E. Sapogova, Scientific Pap. of The Witelon St. Univer. of App. Scien. in Legnica. 11(2), 29-43 (2014)

3. V. Tatenko, Metodologiya sub'yektno-vchinkovogo pidhodu: socialno-psihologichnij vimir (Methodology of subject-action approach: sociopsychological dimension). (Milenium, Kiyiv 2017).

4. N.M. Tokareva, Dissertation, Institute of Psychology, Kyiv, 2015

5. S.B. Kuzlkova, S.V. Puhno, Probl. suchasn. psiholog. 1(15), 72-77. (2019). doi:10.26661/23104368-2019-1-15-11

6. O.V. Lishin, Prakt. psiholog. ta soc. robota $12,23-$ 29 (2010)

7. S.A. Merzakanov, Istor. i soc.-obrazovat. mysl. 6(22), 128-132 (2013)

8. G.V. Dyakonov, Osnovyi dialogicheskogo podhoda $v$ psihologicheskoy nauke i praktike (The basics of the dialogical approach in psychological science and practice). (RIO KGPU im. V. Vinnichenka, Kirovograd, 2007)

9. O.G. Ivanovskaya, Semanticheskij rezonans $i$ ponimanie tekstov (Semantic resonance and understanding of texts). (Rech, Sankt-Peterburg, 2011)

10. N.G. Uskova, Dissertation, MSU, Moskva, 2003

11. N. Tokareva, Psycholog. Zesz. Nauk. (Zielona Gora), 1, 35-48 (2018)

12. T.N. Ushakova, Rozhdenie slova: Problemy psihologii rechi i psiholingvistiki (Birth of a word: Problems of speech psychology and psycholinguistics). (Institut psihologii RAN, Moskva, 2011)

13. S. L. Frank, Vopr. filosof., 6, 68-131 (1990)

14. T.D. Sherban, Dissertation, Institute of Psychology, Kyiv, 2005

15. N. Fairclough, Discourse and Social Change. (Polity Press, Cambridge, 1992).

16. H.J.M. Hermans, Cult. \& Psychol., 7(3), 243-281 (2001)

17. H.J.M. Hermans, J. of Construct. Psycholog. 16(2), 89-130 (2003)

18. M.M. Bahtin, Estetika slovesnogo tvorchestva (Aesthetics of verbal creativity). (Iskusstvo, Moskva, 1979)

19. M.M. Bahtin, Avtor i geroy: K filosofskim osnovam gumanitarnyih nauk (Author and hero: To the philosophical foundations of the humanities). (Azbuka, Sankt-Peterburg, 2000) 
20. L.A. Auhadeeva, Filolog. \& Cult. 1(27), 226-231 (2012)

21. A.Yu. Sutugin, T.G. Muhina, Mir nauki, kult., obrazov. 2(51), 121-124 (2015)

22. L. Nystedt, in Toward a psychology of situations: an interactional perspective, ed. by D.Magnusson (Lawrence Erlbaum, Hillsdale, 1981), pp. 375-391

23. Zh.T. Toshenko, Sociolog. vlasti 2, 6-21 (2011)

24. E.M. Karimulaeva, A.M. Kurbanova, Mir nauki, kult., obrazov. 6 (67), 52-54 (2017)

25. V.A. Yasvin, Obrazovatelnaya sreda: ot modelirovaniya $k$ proektirovaniyu. (Educational environment: from modeling to design). (Smysl, Moskva, 2001)

26. N.P. Fetiskin, V.V. Kozlov, G.M. Manujlov, Socialno-psihologicheskaya diagnostika razvitiya lichnosti $i$ malyh grupp (Socio-psychological diagnosis of the development of personality and small groups). (Izd-vo Instituta Psihoterapii, Moskva, 2002) 